\title{
Nucleotides Cytidine and Uridine Associated with Vitamin BI2 vs B-Complex Vitamins in the Treatment of Low Back Pain: The NUBES Study
}

This article was published in the following Dove Press journal: Journal of Pain Research

\author{
Marco Antonio Naslausky Mibielli (iD) \\ Carlos Pereira Nunes (iD) ${ }^{1,2}$ \\ Henrique Goldberg (D) $^{3}$ \\ Luiz Buchman ${ }^{2}$ \\ Lisa Oliveira iD $^{4}$ \\ Spyros GE Mezitis ${ }^{5}$ \\ Fernanda Wajnzstajn ${ }^{6}$ \\ Renato Kaufman ${ }^{3}$ \\ Rafael Nigri iD $^{7}$ \\ Natasha Cytrynbaum (iD) ${ }^{3}$ \\ Karin Soares Cunha ${ }^{8}$ \\ Alessandra Santos ${ }^{4}$ \\ Stephanie Wrobel Goldberg ${ }^{9}$ \\ Natália Carvalho Platenik' \\ Helio Rzetelna ${ }^{10}$ \\ Daniel Bertoluci Futuro (iD) ${ }^{\prime}$ \\ Adenilson de Souza Da Fonseca' \\ Mauro Geller (ID) 1,3,4 \\ 'UNIFESO Medical School, Teresópolis, \\ Brazil; ${ }^{2}$ UERJ Medical School, Rio De \\ Janeiro, Brazil; ${ }^{3}$ Instituto De Pós- \\ Graduação Médica Carlos Chagas (ICC), \\ Rio De Janeiro, Brazil; ${ }^{4}$ Federal University \\ of Rio De Janeiro (UFRJ), Rio De Janeiro, \\ Brazil; ${ }^{5} \mathrm{New}$ York-Presbyterian Hospital/ \\ Weill-Cornell Medical Center, New York, \\ NY, USA; ${ }^{6}$ Neurology Department, \\ UConn Health, Farmington, CT, USA; \\ ${ }^{7}$ Department of Medicine, Rutgers New \\ Jersey Medical School, Newark, NJ, USA; \\ ${ }^{8}$ Pathology Department, Universidade \\ Federal Fluminense (UFF) Medical School, \\ Niterói, Brazil; ${ }^{9}$ Tufts Medical Center, \\ Boston, MA, USA; ${ }^{10}$ Santa Casa Da \\ Misericórdia Do Rio De Janeiro, Rio De \\ Janeiro, Brazil
}

Correspondence: Mauro Geller Av. Ataulfo de Paiva, 135/702 Rio de Janeiro, 22440-90I, Brazil Tel +55-2I-3875-6660

Email maurogeller@gmail.com
Purpose: We report the results of low back pain treatment using a combination of nucleotides, uridine (UTP), cytidine (CMP) and vitamin $\mathrm{B}_{12}$, vs a combination of vitamins $\mathrm{B}_{1}, \mathrm{~B}_{6}$, and $\mathrm{B}_{12}$.

Patients and Methods: Randomized, double-blind, controlled trial, of a 60-day oral treatment: Group A $(n=317)$ receiving nucleotides $+B_{12}$ and Group B $(n=317)$ receiving B vitamins. The primary endpoint was the percentage of subjects in each group presenting adverse events (AEs). Secondary endpoints were visual analog scale (VAS) pain scores at Visit 2 (day 30) and Visit 3 (day 60) in relation to pretreatment values, Roland-Morris Questionnaire (RMQ) scores and finger-to-floor distance (FFD) (percentage of subjects per group presenting improvement $\geq 5$ points and $\geq 3 \mathrm{~cm}$, respectively).

Results: Seventy-five (24\%) and $105(33 \%)$ subjects $(P=0.21)$ presented 133 and 241 AEs, with $3159 \%$ of subjects presenting $\geq 2$ AEs $(P=0.0019)$ in Group A and Group B, respectively. Twenty-four subjects in Group B were discontinued due to AEs, while no AE-related discontinuations occurred in Group A $(P<0.0001)$. VAS score reduction after 30 and 60 days of treatment was statistically significant $(P<0.0001)$ in both groups, with Group A showing greater reduction at Visit $2(P<0.0001)$. RMQ score improvement $\geq 5$ points occurred in $99 \%$ of subjects from each group, and FFD improvement $\geq 3 \mathrm{~cm}$ occurred in all subjects.

Conclusion: Treatment with nucleotides $+\mathrm{B}_{12}$ was associated with a lower number of total AEs, fewer AEs per subject, and no AE-related treatment discontinuation. Pain intensity (VAS) reduction was superior at 30 days of treatment in the nucleotides $+\mathrm{B}_{12}$ group and equivalent between groups at 60 days of treatment. Improvements in efficacy measures RMQ and FFD were observed in both groups at treatment days 30 and 60.

Keywords: low back pain, uridine, cytidine, vitamin $\mathrm{B}_{1}$, vitamin $\mathrm{B}_{6}$, vitamin $\mathrm{B}_{12}$

\section{Introduction}

Low back pain is a very common condition arising from strains or sprains to the muscles/ligaments of the lumbar region, described as pain, muscle tension, or stiffness in the region below the costal margin and above the inferior gluteal folds with or without accompanying leg pain. ${ }^{1}$ Low back pain is often associated with trauma, sudden movements, or poor body mechanics, with an estimated $84 \%$ of the general population experiencing this condition at least once during adulthood. ${ }^{2}$ In up to $90 \%$ of cases, low back pain is nonspecific, presenting in the absence of a detectable pathoanatomical cause. ${ }^{3,4}$ Low back pain is characterized by duration as acute (lasting up to 
four weeks), subacute (lasting between four and 12 weeks), and chronic (persisting for 12 weeks or more). ${ }^{5}$

Contributing factors associated with low back pain include age - with the highest incidence in the third decade of life and increasing overall prevalence until the age of 60-65 years - educational status, psychosocial status, job satisfaction, occupational aspects, and obesity. ${ }^{6}$ Although often a self-limited condition not requiring active medical treatment, low back pain is one of the most common reasons for physician visits worldwide, leads the conditions associated with increased limitations to daily activities and missed work, and carries a significant direct and indirect economic burden at the individual, family, community, industry, and government levels. ${ }^{1,6,7}$

Treatment of low back pain aims to control pain and maintain function, and includes pharmacological and nonpharmacological therapies. ${ }^{4}$ Frequently used pharmacologic therapies for low back pain include nonsteroidal antiinflammatory drugs (NSAIDs), acetaminophen, tramadol, muscle relaxants, and antidepressants. However, those substances could have severe adverse effects. ${ }^{8}$

Evidence from previous exploratory clinical studies using either the combination of nucleotides and vitamin $\mathrm{B}_{12}$ or the $\mathrm{B}$ vitamins $\left(\mathrm{B}_{1}, \mathrm{~B}_{6}\right.$, and $\left.\mathrm{B}_{12}\right)$ has demonstrated symptomatic and functional improvement among patients treated for painful conditions including neuralgia, neuropathic pain manifestations, low back pain, and osteoarthritis-related pain..$^{9-14}$ The objective of this study was to compare the clinical tolerability and efficacy of the combination of uridine triphosphate, cytidine monophosphate and hydroxocobalamin vs the combination of thiamine nitrate, pyridoxine hydrochloride, and cyanocobalamin in patients presenting low back pain, over a 60 -day treatment period.

\section{Materials and Methods Study Design}

This double-blind, randomized, parallel-group, prospective study was performed at UNIFESO Medical School facilities and hospital in Rio de Janeiro, Brazil from April 2016 to March 2017.

The primary objective of the study was to evaluate the tolerability of the interventions in the treatment of low back pain. The secondary objective was to evaluate the efficacy of the interventions in the treatment of low back pain.
Written informed consent was obtained from each patient. The protocol was conducted in accordance with the Declaration of Helsinki and Good Clinical Practices and was approved by local independent ethics committee (Centro Universitário Serra dos Órgãos - UNIFESOapproval no. 1.295.147). This study is registered with the ClinicalTrials.gov identifier NCT 02640417.

\section{Patient Population}

Patients were included if they met the following criteria: patients of both genders, age $\geq 18$ years, clinical presentation of acute low back pain - duration of $\leq 3$ days from screening date, with and without functional alteration, with medium severity, defined as visual analog pain (VAS) scale score of $20-80 \mathrm{~mm}$. Women of childbearing potential were to use adequate birth control methods throughout the duration of the study.

The main exclusion criteria were: known allergy or hypersensitivity to any component of the study drugs; need for surgical treatment; concomitant treatment with other analgesics; clinically significant laboratory alterations; gastric or duodenal ulcer; gastrointestinal, cerebrovascular or other bleeding; women who were pregnant, breastfeeding or of child-bearing potential not using acceptable birth control methods; and any disease or condition rendering the subject incompatible with participation in the trial.

\section{Study Procedures}

Subjects were treated on an ambulatory basis. The study included three visits: pretreatment, Visit 2 (after 30 days of treatment) and Visit 3 (after 60 days of treatment). Each study visit consisted of a physical examination and vital signs measurement, laboratory testing, and low back pain and functionality assessments. These variables included: a $100 \mathrm{~mm}$ VAS (ranging from $0=$ "no pain" to $100=$ "maximum pain intensity"); the 24-item Roland Morris Low Back Pain and Disability Questionnaire (RMQ) translated and validated in Brazilian Portuguese, consisting of 24 items assessing the impact of low back pain on functional activities, scored with 1 point for each item endorsed, for a total score ranging from 0 to 24 points, with higher scores representing higher levels of pain-related disability; ${ }^{15,16}$ as well as a finger-to-floor distance (FFD) evaluation in which the subject was asked to plant his/her feet firmly on the floor and lean forward as far as possible with arms outstretched to the front, and the distance between the subject's middle finger and the floor was measured and 
recorded in centimeters. At each study visit, subjects were asked to rate their overall pain condition at the time of the visit on a scale of 1 to 10 points ( 1 point=worst evaluation and 10 points=best evaluation). The investigator also rated subject's overall condition on a scale of $1-10$ points (1 point $=$ worst evaluation and 10 points $=$ best evaluation) at each study visit.

At the final study visit, the investigator also evaluated overall treatment efficacy and tolerability using a fourlevel scale (poor, acceptable, good, and very good). Adverse event and compliance monitoring were performed throughout the study period.

The study was blinded both for subjects and investigators. There was a unique packaging and labelling for the treatment units with no identification of allocated study drug. Randomization to study drug groups was generated using random-allocation software. Randomization was performed sequentially for two groups, in blocks of 10 , with a 1:1 ratio between the treatment groups.

\section{Study Drugs}

Subjects were randomized in order of arrival at the study center into one of two treatment groups. Group A received capsules containing active treatment: $1.5 \mathrm{mg}$ uridine triphosphate trisodium (equivalent to $0.665 \mathrm{mg}$ uridine) $+2.5 \mathrm{mg}$ cytidine monophosphate disodium (equivalent to $1.656 \mathrm{mg}$ cytidine) $+1000 \mu \mathrm{g}$ hydroxocobalamin (Etna ${ }^{\circledR}$, Laboratório Gross, Rio de Janeiro, RJ, Brazil). Group B received coated tablets containing active treatment: $100 \mathrm{mg}$ thiamine $+100 \mathrm{mg}$ pyridoxine $+5000 \mu \mathrm{g}$ cyanocobalamin (Citoneurin ${ }^{\circledR}$, Merck, Rio de Janeiro, RJ, Brazil). In order to maintain blinding, each subject also received dummy treatments identical to active treatment of the other group. Subjects in Group A received dummy coated tablets and subjects in Group B received dummy capsules. All subjects were instructed to take two capsules and one coated tablet, three times per day.

\section{Statistical Analysis}

The statistical analysis plan was approved and signed before the clinical database lock and treatment unblinding for the study. Two analysis populations were defined: the intent-to-treat (ITT) population included all randomized patients who received at least one dose of treatment; the safety population included all patients who received at least one dose of treatment. The safety population was the population evaluated for the primary (safety) endpoint, while the ITT population was the primary population for efficacy assessment.

The primary objective of this study was to evaluate the tolerability of the interventions in the treatment of low back pain. The primary endpoint was the percentage of subjects in each treatment group presenting with adverse events. The number of subjects included in this study was calculated taking into account treatment-related adverse event (AE) incidence reported from previous studies performed by our group with both combinations, with estimated $\mathrm{AE}$ rate difference of -0.12 between treatments $\left(0.14\right.$ in nucleotides $+B_{12}$ treatment vs 0.26 in B vitamin combination treatment groups), with the null hypothesis that the proportion of subjects presenting AEs would be identical in both populations. The criteria for significance (alpha) was determined at 0.050 and the test was two-tailed. With a sample size of 232 subjects per group, the study had a power of $90.1 \%$ to generate a statistically significant result, with a proportional between-group difference estimated at $\pm 0.07(95 \% \mathrm{CI}:-0.19,-0.05)$. With an estimated rate of $37 \%$ major deviations, the total number of subjects to be included was 317 per group.

The secondary endpoints analyzed in the ITT population at each visit were RMQ scores (percentage of subjects in each treatment group presenting improvement $\geq 5$ points), VAS pain scores at Visit 2 and Visit 3 in relation to pretreatment values, and FFD (percentage of subjects in each treatment group presenting improvement of $>3 \mathrm{~cm}$ in FFD in relation to pretreatment values).

Data analysis was performed using the software GraphPad Prism version 8.4.3 for Windows (GraphPad Software, San Diego, California USA, www.graphpad. com). Baseline and demographic data were compared between groups using unpaired $t$-test or Fisher's exact test for continuous and categorical variables, respectively. Primary endpoint analysis was performed using the Fisher's exact test. Efficacy evaluations (VAS, FFD, and RMQ) were analyzed for the ITT population using mixed effects analysis followed by Tukey's multiple comparisons test. For comparisons of categorical variables, we used the chi-squared or Fisher's test, while continuous variables were analyzed using the Student's $t$-test or mixed effects analysis for repeated measures. 


\section{Results}

\section{Disposition of Patients}

A total of 1073 subjects were screened and 436 individuals not meeting criteria inclusion were excluded. Six hundred and thirty-four subjects were randomized: 317 in Group A and 317 in Group B (ITTpopulation and safety population) (Figure 1). Early study discontinuations occurred for 28 subjects in Group A and 48 subjects in Group B, with 289 subjects in Group A and 269 subjects in Group B completing the study treatment.

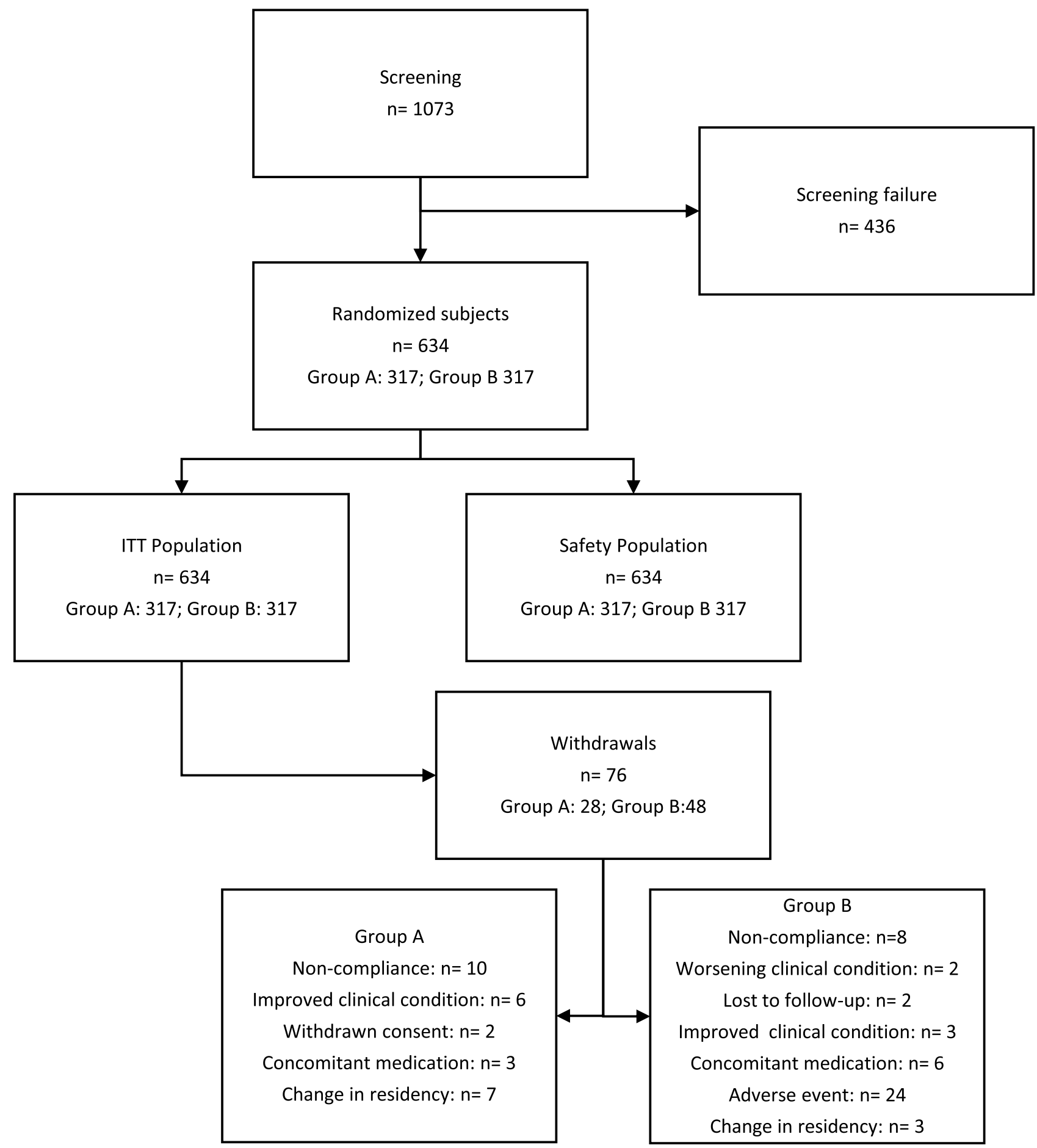

Figure I Flow chart of subjects through the study. 
Table I Characteristics of Patients at Baseline $(n=634)$

\begin{tabular}{|c|c|c|c|}
\hline Variables & $\begin{array}{l}\text { Group A } \\
(n=3 \mid 7)\end{array}$ & $\begin{array}{l}\text { Group B } \\
(n=3 \mid 7)\end{array}$ & $\begin{array}{l}\text { Total } \\
(n=634)\end{array}$ \\
\hline Age (years), mean (SD) & $42.5(11.0)$ & $40.98(9.8)$ & $41.7(10.5)$ \\
\hline \multicolumn{4}{|l|}{ Gender, n (\%) } \\
\hline Male & $191(60.3)$ & $178(56.2)$ & $369(58.2)$ \\
\hline Female & $126(39.7)$ & $139(43.8)$ & $265(4 \mid .8)$ \\
\hline \multicolumn{4}{|l|}{ Ethnicity, n (\%) } \\
\hline Asian & $3(0.9)$ & $5(1.6)$ & $8(1.3)$ \\
\hline Caucasian & $|3|(4 \mid .3)$ & $143(45.1)$ & $274(43.2)$ \\
\hline Black & $59(18.6)$ & $66(20.8)$ & 125 (19.7) \\
\hline Brown & $124(39.1)$ & $103(32.5)$ & $227(35.8)$ \\
\hline Body mass index $\left(\mathrm{kg} / \mathrm{m}^{2}\right)$, mean $(\mathrm{SD})$ & $25.7(3.2)$ & $25.7(3)$ & $25.7(3.1)$ \\
\hline Height $(\mathrm{cm})$, mean (SD) & $169.6(9.1)$ & $168.9(8.5)$ & $169.3(8.8)$ \\
\hline Weight $(\mathrm{cm})$, mean (SD) & $74.5(13.7)$ & $73.5(12.4)$ & $74.0(13.1)$ \\
\hline Heart rate (bpm), mean (SD) & $69.2(5.6)$ & $69.2(6.2)$ & $69.2(5.9)$ \\
\hline Respiratory rate (ipm), mean (SD) & $15.5(2.04)$ & $15.4(2.2)$ & $15.5(2.1)$ \\
\hline Systolic blood pressure $(\mathrm{mmHg})$, mean (SD) & $122.7(8.0)$ & $121.7(7.8)$ & $122.2(7.9)$ \\
\hline Diastolic blood pressure $(\mathrm{mmHg})$, mean (SD) & $78.4(8.5)$ & $77.0(8.9)$ & $77.7(8.7)$ \\
\hline
\end{tabular}

Notes: Group $A$ : subjects treated with uridine, cytidine, and vitamin $B_{12}$. Group $B$ : subjects treated with vitamins $B_{1}, B_{6}$, and $B_{12}$.

Abbreviations: bpm, beats per minute; ipm, inspirations per minute, $\mathrm{mmHg}$, millimeters of mercury.

\section{Baseline Characteristics of Patients}

Demographic and baseline characteristics of the study population are presented in Table 1. Demographic and clinical data were comparable at baseline between treatment groups (with the exception of mean diastolic blood pressure which was higher in Group A and a higher

Table 2 Frequency of Adverse Events Reported in Each Treatment Group by MedDRA System-Organ-Class (SOC)

\begin{tabular}{|c|c|c|c|c|}
\hline \multirow[t]{2}{*}{ Adverse event (SOC) } & \multicolumn{2}{|l|}{ Group A } & \multicolumn{2}{|c|}{ Group B } \\
\hline & $\begin{array}{l}\text { Visit } 2 \\
(n=3 I)^{a}\end{array}$ & $\begin{array}{l}\text { Visit } 3 \\
(n=62)\end{array}$ & $\begin{array}{l}\text { Visit } 2 \\
(n=46)\end{array}$ & $\begin{array}{l}\text { Visit } 3 \\
(n=80)\end{array}$ \\
\hline Cardiac disorders & 0 & 1 & 2 & 0 \\
\hline Ear and labyrinth disorders & I & 3 & 6 & 2 \\
\hline Eye disorders & 0 & 3 & 0 & 0 \\
\hline Gastrointestinal disorders & 0 & 0 & 7 & 15 \\
\hline General disorders and administration site conditions & 2 & 3 & I & 9 \\
\hline Infections and infestations & 0 & 2 & 0 & 0 \\
\hline Investigations & 1 & 3 & 8 & 12 \\
\hline Metabolism and nutrition disorders & I & 2 & 2 & 2 \\
\hline Musculoskeletal and connective tissue disorders & 1 & 0 & 6 & 16 \\
\hline Nervous system disorders & 5 & 10 & 15 & 16 \\
\hline Psychiatric disorders & 3 & 7 & 5 & 3 \\
\hline Renal and urinary disorders & 16 & 59 & 23 & 71 \\
\hline Respiratory, thoracic and mediastinal disorders & 3 & 2 & 0 & 0 \\
\hline Skin and subcutaneous tissue disorders & 0 & 3 & 6 & 2 \\
\hline Vascular disorders & I & 1 & 5 & 7 \\
\hline Total number of AEs & 34 & 99 & 86 & 155 \\
\hline
\end{tabular}

Notes: Group A: subjects treated with uridine, cytidine, and vitamin $B_{12}$. Group B: subjects treated with vitamins $B_{1}, B_{6}$, and $B_{12}$. ${ }^{a}$ Number of subjects reporting $A E s$ in each group at each study visit. 
number of subjects reporting previous episodes of low back pain in Group A).

\section{Safety}

During the study treatment period, 75 (24\%) subjects in Group A and 105 subjects (33\%) in Group B reported AEs. While the percentage of subjects in the safety population reporting AEs was higher in Group B, the difference between groups did not reach statistical significance $(P=0.21)$. The majority of AEs reported in both treatment groups affected the gastrointestinal tract (Table 2).

A total of 374 AEs was reported during the treatment period, of which 133 (35.6\%) occurred in Group A and 241 $(65.4 \%)$ in Group B. The distribution of number of AEs per subject during the study treatment period showed a larger percentage of subjects in Group B presenting two or more AEs $(\chi 2=17.04 ; \mathrm{df}=4 ; P=0.002)$. No serious $\mathrm{AE}$ was reported. Two severe AEs (vomiting, headache) were reported in Group $A$, and 13 severe AEs were reported in Group B: headache $(n=3)$, hypokalemia $(n=2)$, nausea $(n=2)$, hot flushes $(n=2)$, muscle cramps $(n=1)$, muscle weakness $(n=1)$, loss of appetite $(n=1)$, and vomiting $(n=1)$. At least one AE possibly or probably related to study drugs was reported in 17 (5.4\%) subjects in Group A and 38 (12\%) subjects in Group B; despite this numerical difference, the between-group difference was not statistically significant $(P=0.13)$.

While there were no AEs leading to treatment discontinuation in Group A, 24 patients in Group B presented at least one AE leading to treatment discontinuation, a statistically significant between-group difference $(\chi 2=24.86 ; \mathrm{df}=1 ; P<0.0001)$. These AEs were: hypokalemia $(n=5)$; nausea $(n=3)$; muscle cramps, headache, hyperuricemia, loss of appetite, generalized pruritus, and vertigo $(n=2)$; in addition to progressive numbness in the hands, tactile alterations in the hands, cramps, abdominal discomfort, gastric discomfort, numbness in face, numbness in hands, muscle spasms, tingling sensation in upper limbs, facial tingling sensation, muscle weakness, gout, hypertension, insomnia, palpitations, polyuria, paraesthesia in hands, pruritus and pruritus on upper limbs $(n=1)$ (more than one $\mathrm{AE}$ could be reported per patient).

\section{VAS Pain}

Baseline VAS pain scores were $51.4 \mathrm{~mm}( \pm 11.4$; 95\%CI: 50.2 , $52.7)$ in Group A and $52.6 \mathrm{~mm}( \pm 11.3$; 95\% CI: 51.4, 53.9) in Group B. Mean VAS scores at each study visit are displayed in Figure 2. Mean VAS pain scores at Visit 2 were $8.2 \mathrm{~mm} \pm 9.4$
VAS Scores

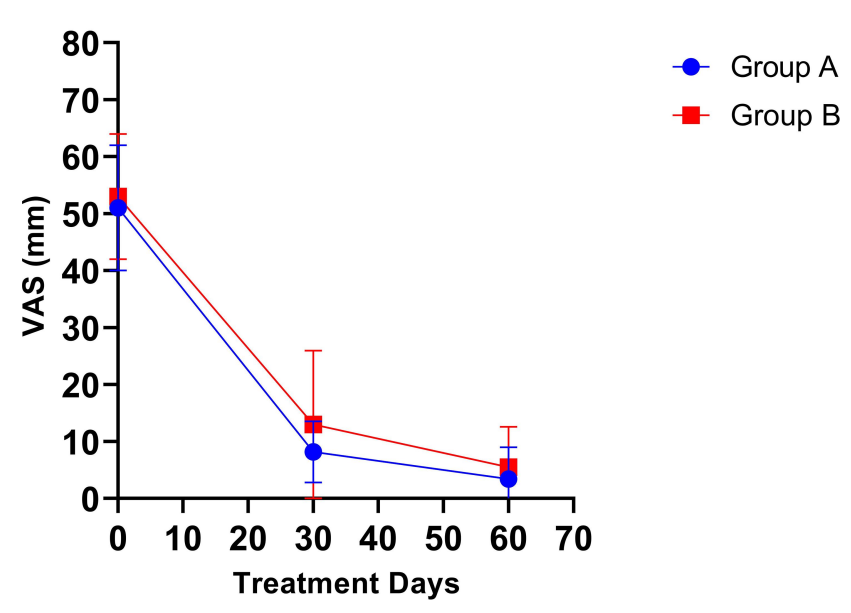

Figure 2 Mean visual analog scores for pain, for treatment groups $A$ and $B$. Notes: Group $(A)$ subjects treated with uridine, cytidine, and vitamin $B_{12}$. Group (B) Subjects treated with vitamins $B_{1}, B_{6}$, and $B_{12}$.

Abbreviations: VAS, visual analog scale; V2, Visit 2 (after 30 days of treatment); V3, Visit 3, (after 60 days of treatment).

(95\%CI: 7.1, 9.2) in Group A, with a mean difference from pretreatment of 43.3 (95\%CI: 41.5, 45.1; $P<0.0001)$ while in Group B, mean Visit 2 VAS pain score was $12.6 \mathrm{~mm} \pm 13.2$ (95\%CI: 11.2, 14.1), with a mean difference from pretreatment of 39.96 (95\%CI: 37.8, 42.16; $P<0.0001)$. At Visit 2 , the mean difference in VAS scores was higher among patients in Group A compared to that in Group B $(-4.5 ; 95 \% \mathrm{CI}:-7.2,-1.8$; $P<0.0001)$.

At Visit 3, mean VAS pain scores in Group A were further reduced to $3.4 \mathrm{~mm} \pm 5.6$ (95\% CI: 2.7, 4.0) in Group A, mean difference in relation to pretreatment of 48.1 (95\%CI: 46.3, 49.9) and $5.5 \pm 7.1$ (95\%CI: 4.7, 6.4) in Group B, reduction from pretreatment of 47.1 (95\%CI: 45.2 , 49.0). VAS score reduction from pretreatment at Visit 3 was statistically significant $(P<0.0001)$ for both Group A and Group B. At Visit 3, mean difference when comparing VAS score reduction from pretreatment values was higher for Group A $(-2.1 ; 95 \% \mathrm{CI}=-3.7,-0.6$; $P=0.002$ ).

\section{Finger-to-Floor Distance}

Mean pretreatment FD was $28.1 \mathrm{~cm}( \pm 7.4$; 95\%CI: 27.3 , $28.9)$ in Group $\mathrm{A}$ and $27.3 \mathrm{~cm}( \pm 7.5$; 95\%CI: 26.5 , 28.1) in Group B. All treated subjects had improvement of $\geq 3 \mathrm{~cm}$ in FFD at Visit 3 in relation to pretreatment values (Table 3). Change in FFD from pretreatment was statistically significant $(P<0.001)$ in both groups at 30 days (Visit 2) and 60 days (Visit 3). 
Table 3 Changes in Finger-to-Floor Distance During Treatment (ITT Population)

\begin{tabular}{|c|c|c|c|}
\hline Treatment Group/Study Visits & Mean FFD (SD) & $\begin{array}{l}\text { Mean Difference } \\
(95 \% \mathrm{Cl})\end{array}$ & $P$-value ${ }^{b}$ \\
\hline \multicolumn{4}{|l|}{ Group A $(n=289)$} \\
\hline Pretreatment & $28.1(7.4)$ & & \\
\hline Visit 2 & $17.4(8.0)$ & $10.7(9.8,11.7)$ & $<0.0001$ \\
\hline Visit 3 & $13.5(7.7)$ & $14.6(13.5,15.8)$ & $<0.0001$ \\
\hline \multicolumn{4}{|l|}{ Group B $(n=269)$} \\
\hline Pretreatment & $27.3(7.5)$ & & \\
\hline Visit 2 & $14.5(8.2)$ & I2.8 (II.7, I3.9) & $<0.0001$ \\
\hline Visit 3 & $9.6(6.2)$ & $17.7(16.6,18.9)$ & $<0.0001$ \\
\hline
\end{tabular}

Notes: Group A: subjects treated with uridine, cytidine, and vitamin $B_{12}$. Group $B$ : subjects treated with vitamins $B_{1}, B_{6}$, and $B_{12} .{ }^{a}$ From pretreatment; ${ }^{b}$ Tukey's multiple comparisons test.

Abbreviation: FFD, finger-to-floor distance $(\mathrm{cm})$.

\section{Roland-Morris Questionnaire}

Pretreatment RMQ scores were $14.2( \pm 3.6$; 95\%CI: 13.8 , $14.6)$ in Group A and $13.4( \pm 3.8$; 95\%CI: $13.0,13.8)$. At Visit 3, 287 (98.9\%) subjects in Group A and 265 (97.8\%) subjects in Group B showed improvement of $\geq 5$ points in RMQ scores. Mean scores at Visit 2 were 2.3 points $( \pm 3.0$; 95\%CI: 1.9, 2.6) in Group A mean difference of 11.9 points from pretreatment $(95 \% \mathrm{CI}: 11.3,12.5)$ and 3.3
$( \pm 3.8$; 95\% CI: 2.9, 3.7); in Group B mean difference of 10.1 points from pretreatment (95\%CI: $9.5,10.8)$.

A further score improvement at Visit 3 was observed in both treatment groups, with Group A mean score of $0.9 \pm 1.8$ (95\% CI: $0.7,1.1)$ and Group B mean score of $1.3 \pm 2.3(95 \% \mathrm{CI}$ : 1.1, 1.6). Visit 3 score mean differences in relation to pretreatment values were 12.8 points $(95 \% \mathrm{CI}: 12.1,13.6)$ in Group A and 12.1 points $(95 \% \mathrm{CI}: 11.4,12.7)$ in Group B.

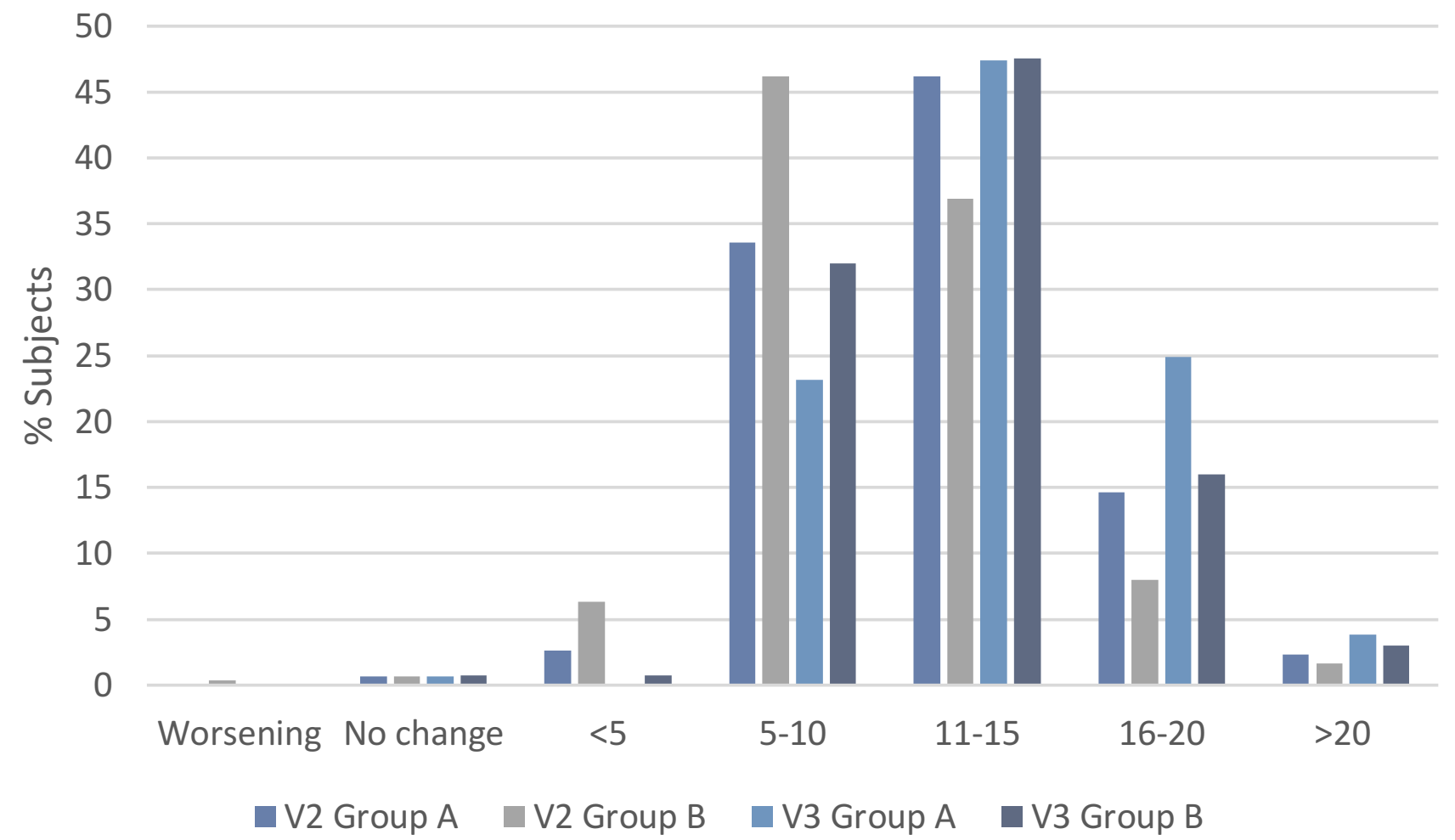

Figure 3 Distribution of RMQ score changes from pretreatment at Visits 2 and 3.

Notes: Graph displaying percentage of subjects in each treatment group with worsening, no change, and improvement (categorized by $<5$, 5-10 points, II-I5 points, $16-20$ points and $>20$ points).

Abbreviations: RMQ, Roland-Morris Questionnaire; V2, Visit 2 (after 30 days of treatment); V3, Visit 3 (after 60 days of treatment). 
Score improvements within each treatment group were statistically significant $(P<0.001)$ at Visit 2 and Visit 3 in relation to pretreatment scores in both treatment groups. When comparing scores between treatment groups, there was a greater RMQ score reduction in Group A at Visit 2 $(P=0.005)$ but not at Visit $3(P=0.09)$ in relation to Group B scores (Figure 3).

\section{Compliance to Treatment}

Drug compliance data was available for 589 subjects at Visit 2, with median compliance of $103.0 \%$ for tablets (95\%CI: $103.5-104.1)$ and $103.0 \%$ for capsules $(95 \% \mathrm{CI}$ : 103.3-103.8). At Visit 3, median compliance (data from 558 subjects) was $100.0 \%$ (95\%CI: $99.8-100.1)$ for tablets and $100.0 \%$ for capsules (95\%CI: $99.7-100)$.

\section{Patient Assessment of Overall Pain Condition}

Pretreatment patient overall assessment scores were comparable between treatment groups $(\chi 2=2.9 ; \mathrm{df}=3$; $P=0.96$ ). At Visits 2 and 3, the scores of this assessment improved within each treatment group $(P<0.0001$ for both groups), with no statistically significance between treatment groups in percentage of subjects presenting improvement ( $P=0.06$ at Visit 2 and $P=0.54$ at Visit 3 ).

\section{Physician Assessment of Overall Condition}

Physician overall assessment scores were comparable between treatment groups at pretreatment $(P=0.72)$. At Visits 2 and 3, the scores of this assessment improved within each treatment group ( $P<0.0001$ for both groups), with no statistically significance between treatment groups in percentage of subjects presenting improvement $(P=0.06$ at Visit 2 and $P=0.33$ at Visit 3).

\section{Investigators Assessment of Overall Treatment Efficacy and Tolerability}

The global investigator evaluation of efficacy and tolerability was comparable for the two treatment groups. Overall, efficacy was rated as good-very good during the study by a large majority of investigators: $94 \%$ in Group A and $90 \%$ in Group B $(P=0.36)$.

\section{Discussion}

We report here on the first comparative study of the combination of nucleotides plus vitamin $\mathrm{B}_{12}$, vs the combination of vitamins $\mathrm{B}_{1}, \mathrm{~B}_{6}$, and $\mathrm{B}_{12}$ over a 60 -day treatment period among patients with low back pain. The two treatments were comparable in the safety evaluation (primary study endpoint) as assessed by AE incidence among treated subjects. However, the number of AEs per subject was significantly higher among patients treated with the combination of vitamins $\mathrm{B}_{1}, \mathrm{~B}_{6}$, and $\mathrm{B}_{12}$, and only in the $\mathrm{B}$ vitamin combination group was there interruption of treatment due to AEs. No serious AEs were reported during the treatment period.

Previous studies in smaller populations assessing these combinations utilized shorter treatment periods of up to 30 days, ${ }^{9-13}$ however the longer treatment period employed in the present study does not appear to have resulted in a higher rate of $\mathrm{AE}$ occurrence. Comparing the results of the present study with those of the study by Goldberg et al, total AE rate in that study among 200 subjects who received the nucleotide+vitamin $\mathrm{B}_{12}$ combination over 30 days of treatment was $19 \%$, while total $\mathrm{AE}$ rate among subjects receiving the same treatment in the present study over 60 days was $24 \%(P=0.49) .{ }^{13}$

The AEs observed during treatment were in keeping with the known safety profile of both treatments, with no previously unreported treatment-related AEs registered throughout the treatment period in either treatment group. Gastrointestinal AEs were the most frequently reported AEs in both treatment groups, in keeping with the reported AE profile of the previous studies employing these combinations. Known side effects associated with vitamin $\mathrm{B}_{12}$ administration include allergic hypersensitivity reactions, with skin eruptions, rash and pruritus, hypokalemia, fever, chills, hot flushing, dizziness, malaise, and tremor has also been reported. ${ }^{17,18}$ Previously reported side effects of thiamine include skin alterations (discoloration, hives, pruritus), hyperhidrosis, restlessness, and gastrointestinal symptoms, especially nausea. Known side effects of pyridoxine include gastrointestinal symptoms, numbness and tingling, headache, sleepiness, and sensory nerve damage (following long-term use of high doses). ${ }^{18}$

In our study, subjects in both treatment groups displayed significant improvement in all low back pain-related evaluation measures in relation to pretreatment status. VAS pain scores decreased significantly after 30 days of treatment within both treatment groups, with a greater score reduction among subjects in Group A compared to those in Group B, although this between-group difference was not observed after 60 days of treatment. The improvement in pain intensity as assessed by the VAS observed at Visit 2 was maintained at Visit 3, with further significant decrease in VAS scores at Visit 3. There was a significant improvement in functionality when assessed by 
the RMQ throughout the treatment period, with greater score reductions observed among subjects treated with the combination of nucleotides+vitamin $B_{12}$. The positive effect on mobility (FFD) seen after 30 days of treatment was maintained or further improved at 60 days of treatment within both treatment groups. The same was observed for pain intensity, VAS and RMQ scores. The patient and investigator global assessments also improved significantly throughout the treatment period. These observations support the continued treatment for the period of 60 days among patients with low back pain.

The use of nucleotides and vitamin $\mathrm{B}_{12}$ employed to treat low back pain and other painful conditions has been the subject of continuing investigations, with encouraging results from previous studies. ${ }^{10,13,19}$ In patients with compression neuralgia associated with degenerative orthopedic alterations of the hip and spine, treatment with the combination of nucleotides and vitamin $B_{12}$ resulted in significant pain improvement and increased functionality. ${ }^{10}$ In a study evaluating the use of the combination of nucleotides and vitamin $B_{12}$ in patients with alcoholic polyneuropathy, pain reduction and improvement in motor coordination was reported following intramuscular injection of the combination for six days followed by 30-day oral treatment. ${ }^{11}$ In a previous study of peripheral neuropathies including low back pain, the same combination of nucleotides and vitamin $B_{12}$ utilized in the present study was shown to be superior to vitamin $\mathrm{B}_{12}$ monotherapy in pain relief as assessed by a $100 \mathrm{~mm}$ VAS during a 30-day treatment period. ${ }^{13}$

While the pyrimidine nucleotides cytidine and uridine lack direct analgesic or anti-inflammatory action, their contribution to symptomatic improvement in conditions involving the peripheral nervous system has been evidenced in preclinical studies following experimentally induced nerve damage. In animal models of induced crush injury, administration of nucleotides was shown to accelerate both axonal and myelin sheath repair of regenerating nerve and muscle fibers, with improvements in nerve fiber conduction velocity. ${ }^{20-22}$ Results of further preclinical investigations have indicated increased nerve conduction velocity, increased levels of neuritic protein neurofilaments, increased axon myelin surface area and thickness, and increased levels of neuronal cell membrane phospholipids phosphatidylcholine and phosphatidylethanolamine following nucleotide administration. ${ }^{23}$ More recently, Chavushyan et al reported increased excitatory and inhibitory responses in rats following sciatic nerve crush treated with the same combination of nucleotides and $\mathrm{B}_{12}$ employed in the present study, with recovery of motor and sensory function comparable to uninjured limbs after 30 days of treatment. ${ }^{24}$

A salvage pathway is one way in which nucleotides (purine and pyrimidine) are synthesized from intermediates in the degradative pathway for nucleotides. Cytidine and uridine are absorbed by cells, and cytidine is deaminated to uridine. Uridine is phosphorylated to form uracil nucleotides by uridine kinase, a monophosphate kinasespecific for uridine monophosphate (UMP), CMP and $\mathrm{dCMP}$ - and an unspecific nucleoside diphosphokinase. Salvage pathway-synthesized UTP may preferably be used for RNA synthesis in cell nuclei and may contribute to a cytosolic free UTP input along with de novo pathway UTP. Free UTP can provide UTP to be stored in granules, or released to act on pyrimidine cell surface receptors. ${ }^{25}$

The mechanisms underlying the therapeutic effects observed following uridine and cytidine administration appear to stem from the nucleotides' impact on the purine $\mathrm{P} 2 \mathrm{Y}$ receptors $\mathrm{P} 2 \mathrm{Y} 1$ and $\mathrm{P} 2 \mathrm{Y} 2$, which in turn have been shown to mediate nucleotide-induced sensory neuron excitation via inhibition of voltage-gated Kv7-family potassium channels via increased intracellular $\mathrm{Ca}^{2+}$, along with facilitation of TRPV1 vanilloid receptors in the dorsal root ganglia, via activation of protein kinase $C{ }^{26}$ Additionally, purine nucleotides have been shown to induce activation of a1AR postsynaptic adrenergic receptors, which are involved in regulation of synaptic transmission, plasticity, and motor activity. ${ }^{27}$

In both previous studies of the combination of nucleotides and vitamin $\mathrm{B}_{12}$ employing vitamin $\mathrm{B}_{12}$ monotherapy as control, improvement in pain and functionality was reported in the control group, ${ }^{10,13}$ which highlights the importance of vitamin $\mathrm{B}_{12}$ in the formulation. Use of intramuscular vitamin $\mathrm{B}_{12}$ monotherapy was evaluated by Mauro et al in the treatment of low back pain in patients presenting mechanical or irritative lumbago, reporting that after a two-week treatment period consisting of once-daily $1000 \mu \mathrm{g}$ vitamin $\mathrm{B}_{12}$ injections, treated subjects experienced a significant decrease in pain and disability that was statistically superior to the placebo-treated control group. ${ }^{28}$ Vitamin $\mathrm{B}_{12}$ has also shown clinical efficacy in the treatment of diabetic neuropathy, demonstrating improvement in pain, paraesthesia, somatosensory and autonomic symptoms, as well as nerve conduction velocity. ${ }^{29-31}$

In the nervous system, Vitamin $\mathrm{B}_{12}$ plays an essential role in myelin synthesis, nerve metabolism, and neuronal regeneration. In preclinical studies performed with rats, vitamin $\mathrm{B}_{12}$ has been demonstrated to exert an effect on nociception and pain response, with accelerated compound 
muscle action potential recovery and dose-dependent reduction of tactile allodynia reported. ${ }^{32-34}$ The proposed mechanisms of action of vitamin $B_{12}$ in pain relief include: promotion of nerve regeneration and/or remyelination by accumulation of exogenous $\mathrm{B}_{12}{ }^{28}$ selective blockade of sensory nerve conduction, ${ }^{35}$ promotion of protein synthesis necessary for nerve regeneration via upregulation of gene transcription. ${ }^{36}$

Vitamins $\mathrm{B}_{1}, \mathrm{~B}_{6}$, and $\mathrm{B}_{12}$ belong to the family of neurotropic B vitamins, playing important roles in the maintenance of nervous system function, and deficiencies of which may result in peripheral nervous system disorders. ${ }^{37}$ Furthermore, evidence from both preclinical and clinical studies has shown that the combination of these $B$ vitamins is effective in the treatment of neuropathic pain and symptoms of neuropathic conditions, even in the absence of deficiencies in these B vitamins. ${ }^{14,37}$

The strong points of this study are mainly the 60-day study duration, the large number of patients and the assessments performed in the context of low back pain. The major study weakness is sponsorship by the manufacturer of the test product, authors acknowledge potential for bias in sponsored studies. Given the more favorable safety with no subjects in the nucleotides+vitamin $\mathrm{B}_{12}$ treatment group discontinuing treatment due to AEs, comparative clinical studies employing this combination in other types of peripheral neuropathies may also be of interest, as treatment periods of 60 days or more with therapeutic doses of B vitamins are often employed in these conditions.

\section{Conclusion}

In conclusion, while a larger percentage of subjects presented AEs in Group B, this difference did not reach statistical significance. However, $>60 \%$ of total AEs occurred in Group B, a higher percentage of subjects in Group B presented two or more AEs during treatment, and AEs causing treatment discontinuation occurred only in the $\mathrm{B}$ vitamin combination group. Pain intensity (VAS) reduction was superior at 30 days of treatment in the nucleotides+vitamin B12 group and equivalent between groups at 60 days of treatment. Improvements in efficacy measures RMQ and FFD were observed in both groups. The additional improvement in pain, mobility, and functionality observed at the final study visit support the continued treatment for the period of 60 days among patients with low back pain.

\section{Data Sharing Statement}

The authors agree to share study data upon request by e-mail to the corresponding author, via e-mail (maurogeller@gmail.com), to investigators whose proposed use of the data has been approved by an independent review committee or ethical committee and who agree to sign a data access agreement. Data to be shared includes individual deidentified participant data and study-related documents (ie, study protocol, informed consent text, or other study documentation requested), for a period of five years from the date of study publication.

\section{Acknowledgments}

The authors thank Prof. Mendel Suchmacher Neto for review of the paper and revision of the statistical analysis. Thanks also to Silvia Maciel, Thainá Zanoon Cruz, and Aline Pacheco for study monitoring.

\section{Disclosure}

This study was sponsored by Laboratório Gross S.A. (Rio de Janeiro, RJ, Brazil). Fernanda Wajnzstajn reports being a PI for a clinical trial sponsored by Alnylam, outside the submitted work. The authors report no other potential conflicts of interest in this work.

\section{References}

1. Golob AL, Wipf JE. Low back pain. Med Clin North Am. 2014;98 (3):405-428. doi:10.1016/j.mena.2014.01.003

2. Hoy D, Brooks P, Blyth F, et al. The epidemiology of low back pain. Best Pract Res Clin Rheumatol. 2010;24:769-781. doi:10.1016/j. berh.2010.10.002

3. Koes BW, van Tulder MW, Thomas S. Diagnosis and treatment of low back pain. BMJ. 2006;332:1430-1434. doi:10.1136/bmj.332.7555. 1430

4. Maher C, Underwood M, Buchbinder R. Non-specific low back pain. Lancet. 2017;389(10070):736-747. doi:10.1016/S0140-6736(16)3 0970-9

5. Chou R. Low Back Pain. Ann Intern Med. 2014;160(11):ITC6-1. doi:10.7326/0003-4819-160-11-201406030-01006

6. Patrick N, Emanski E, Knaub MA. Acute and chronic low back pain. Med Clin North Am. 2014;98(4):777-789. doi:10.1016/j.mena.2014. 03.005

7. Steenstra IA, Verbeek JH, Heymans MW, et al. Prognostic factors for duration of sick leave in patients sick listed with acute low back pain: a systematic review of the literature. Occup Environ Med. 2005;62 (12):851-860.

8. Chou R, Deyo R, Friedly J, et al. Systemic pharmacologic therapies for low back pain: a systematic review for an american college of physicians clinical practice guideline. Ann Intern Med. 2017;166 (7):480-492. doi:10.7326/M16-2458

9. Mibielli MA, Diamante B, Cohen JC, et al. Safety and efficacy of a B-vitamin combination in the treatment of osteoarthritis-related pain. Rev Bras Med. 2007;64(1/2):36-41. 
10. Goldberg H, Scussel AR Jr, Cohen JC, et al. Neural compressioninduced neuralgias: clinical evaluation of the effect of nucleotides associated with vitamin B12. Rev Bras Med. 2009;66(11):380-385.

11. Nunes CP, Scussel AB Jr, Goldberg H, et al. Alcoholic polyneuropathy: clinical assessment of treatment outcomes following therapy with nucleotides and vitamin B12. Res Neurol. 2013;16.

12. Mibielli MA, Nunes CP, Scussel AB Jr, et al. Symptomatic improvement in an acute, non-traumatic spine pain model with a combination of uridine triphosphate, cytidine monophosphate, and hydroxocobalamin. PST. 2014;2(1):6-10.

13. Goldberg H, Mibielli MA, Nunes CP, et al. A double-blind, randomized, comparative study of the use of a combination of uridine triphosphate trisodium, cytidine monophosphate disodium, and hydroxocobalamin, versus isolated treatment with hydroxocobalamin, in patients presenting with compressive neuralgias. J Pain Res. 2017;10:397-404.

14. Hakim M, Kurniani N, Pinzon R, et al. Management of peripheral neuropathy symptoms with a fixed dose combination of high-dose vitamin B1, B6 and B12: A 12-week prospective non-interventional study in Indonesia. Asian J Med Sci. 2018;9(1):32-39. doi:10.3126/ ajms.v9i1.18510

15. Nusbaum L, Natour J, Ferraz M, Goldenberg J. Translation, adaptation and validation of the Roland-Morris questionnaire - Brazil Roland-Morris. Braz J Med Biol Res. 2001;34(2):203-210. doi:10.1590/S0100-879X2001000200007

16. Roland M, Morris R. A study of the natural history of back pain. Part I: development of a reliable and sensitive measure of disability in low-back pain. Spine. 1983;8(2):141-144. doi:10.1097/00007632198303000-00004

17. Uhl W, Nolting A, Golor G, et al. Safety of hydroxocobalamin in healthy volunteers in a randomized, placebo-controlled study. Clin Toxicol. 2006;44((sup1)):17-28. doi:10.1080/15563650600811755

18. Brayfield A, Ed. Martindale: The Complete Drug Reference. 39th ed. London: Pharmaceutical Press; 2017.

19. Serra JP, Veciana MG, Bordas LB. Efectos terapeuticos de una asociacion de C.M.P., U.T.P., y vitamina B12 en cincuenta casos de neuropatias perifericas. $N$ Engl J Med. 1972; VI(64):1-7.

20. Wattig B, Heydenreich F, Schalow G, et al. Nucleotide beschleunigen die nerve regeneration. Z Klin Med. 1991;46:1371-1373.

21. Wattig B, Schalow G, Heydenreich F, et al. Enhancement of nerve fibre regeneration by nucleotides after peripheral nerve crush damage. Electrophysiologic and morphometric investigations. Arzneimittel-Forschung. 1992;42((II)9):1075-1078.

22. Wattig B, Schalow G, Madauss M, et al. Acceleration of nerve and muscle regeneration by administration of nucleotides - electroneurophysiological and morphometrical investigations. Acta Histochem. 1992;(Suppl-Band XLII; S):333-339.

23. Wurtman RJ, Ulus IH, Cansev M, et al. Synaptic proteins and phospholipids are increased in the gerbil brain by administering uridine plus docosahexaenoic acid orally. Brain Res. 2006;1088:8392. doi:10.1016/j.brainres.2006.03.019
24. Chavushyan VA, Gevorgyan LR, Simonyan KV. Assessment of the efficacy of nucleotide therapy after sciatic nerve injury. Neurosci Behav Physiol. 2015;45(7):820-828. doi:10.1007/s11055-015-0149-x

25. Anderson CM, Parkinson FE. Potential signalling roles for UTP and UDP: sources, regulation and release of uracil nucleotides. Trends Pharmacol Sci. 1997;18(10):387-392. doi:10.1016/S0165-6147(97)01106-1

26. Yousuf A, Klinger F, Schicker K, Boehm S. Nucleotides control the excitability of sensory neurons via two P2Y receptors and a bifurcated signaling cascade. Pain. 2011;15(8):1899-1908. doi:10.1016/j. pain.2011.04.016

27. Mukherjee C, Lejkowitz RJ. Desensitization of beta-adrenergic receptors by beta-adrenergic agonists in a cell-free system: resensitization by guanosine 5'-(beta gamma-imino) triphosphate and other purine nucleotides,". Proc Natl Acad Sci USA. 1976;73(5):14941498. doi:10.1073/pnas.73.5.1494

28. Mauro GL, Martorana U, Cataldo P, et al. Vitamin B12 in low back pain: a randomised, double-blind, placebo-controlled study. Eur Rev Med Pharmacol Sci. 2000;4:53-58.

29. Kuwabara S, Nakazawa R, Azuma N, et al. Intravenous methylcobalamin treatment for uremic and diabetic neuropathy in chronic hemodialysis patients. Intern Med. 1999;38(6):472-475. doi:10.2169/ internalmedicine. 38.472

30. Devathasan G, Teo WL, Mylvaganam A. Methylcobalamin in chronic diabetic neuropathy. A double-blind clinical and electrophysiological study. Clin Trials J. 1986;23:130-140.

31. Yaqub BA, Siddique A, Sulimani R. Effects of methylcobalamin on diabetic neuropathy. Clin Neurol Neurosurg. 1992;94:105-111.

32. Wantanabe T, Kaji R, Oka N, et al. Ultra-high dose methylcobalamin promotes nerve regeneration in experimental acrylamide neuropathy. $J$ Neurol Sci. 1994;122:140-143. doi:10.1016/0022-510X(94)90290-9

33. Granados-Soto V, Sánchez-Ramirez G, la Torre MR, et al. Effect of diclofenac on the antiallodynic activity of vitamin B12 in a neuropathic pain model in the rat. Proc West Pharmacol Soc. 2004;47:92-94.

34. Mixcoatl-Zecuatl T, Quinonez-Bastidas GN, Caram-Salas NL, et al. Synergistic antiallodynic interaction between gabapentin or carbamazepine and either benfotiamine or cyanocobalamin in neuropathic rats. Methods Find Exp Clin Pharmacol. 2008;30(6):1-11. doi:10.1358/mf.2008.30.6.1254247

35. Takeshige C, Ando Y, Ando M. Effects of vitamin B12 and aldosterone on the conduction of sensory and motor nerve impulse. Vitamins. 1971;44:272-282.

36. Pfohl-Leszkowicz A, Keith G, Dirheimer G. Effect of cobalamin derivatives on in vitro enzymatic DNA methylation: methylcobalamin can act as a methyl donor. Biochemistry. 1991;30:8045-8051. doi:10.1021/bi00246a024

37. Calderón-Ospina CA, Nava-Mesa MOB. Vitamins in the nervous system: current knowledge of the biochemical modes of action and synergies of thiamine, pyridoxine, and cobalamin. CNS Neurosci Ther. 2019;00:1-9.
Journal of Pain Research

\section{Publish your work in this journal}

The Journal of Pain Research is an international, peer reviewed, open access, online journal that welcomes laboratory and clinical findings in the fields of pain research and the prevention and management of pain. Original research, reviews, symposium reports, hypothesis formation and commentaries are all considered for publication. The manuscript

Submit your manuscript here: https://www.dovepress.com/journal-of-pain-research-journal management system is completely online and includes a very quick and fair peer-review system, which is all easy to use. Visit http:// www.dovepress.com/testimonials.php to read real quotes from published authors. 